Jurnal Indonesia Sosial Teknologi: p-ISSN: 2723 - 6609

e-ISSN : 2745-5254

Vol. 2, No. 9 September 2021

\title{
PERANCANGAN KARTU IDENTITAS BEROBAT ELEKTRONIK DENGAN MENGGUNAKAN VISUAL STUDIO DI RUMAH SAKIT MUHAMMADIYAH BANDUNG
}

\author{
Ridha Robiatul Adhawiyah', Yuyun Yunengsih ${ }^{2}$, Falaah Abdussalaam ${ }^{3}$ \\ Politeknik Piksi Ganesha ${ }^{1,2,3}$ \\ Email: rradhawiyah@piksi.ac.id ${ }^{1}$,yoen1903@gmail.com², \\ falaah_abdussalaam@yahoo.com ${ }^{3}$
}

\begin{abstract}
Abstrak
Pada saat ini perkembangan teknologi semakin berkembang dan maju dalam bidang apa pun,termasuk dalam bidang kesehatan dan ruang lingkup ruma sakit. Tetapi, masih banyaknya metode tradisional (manuals) yang masih digunakan oleh manusia. Dalam ruang lingkup rumah sakit salah satu metode manual yang masih digunakan yaitu kartu identitas berobat. Pembuatankartu identitas berobat yang masih secara manual dengan menggunakan bahan baku berupa kertas. Hal tersebut dapat mengurangi efisien dan efektivitas waktu, sehingga di perlukan adanya perancangan pembuatan kartu identitas berobatsecara modern. Penelitian ini bertujuan untuk merancang kartu identitas berobat menggunakan visual studio 2010 di Rumah Sakit Muhammadiyah Bandung. Metode penelitian yang digunakan adalah metode penelitian kualitatif. Teknik pengumpulan data yang digunakan adalah dengan cara observasi melalui kegiatan wawancara serta dilengkapi dengan kajian pustaka. Beberapa permasalahan yang terjadi selama penulis melakukan praktek kerja lapangan, masih manualnya pembuatan kartu identitas berobat pasien, tidak ada alat printer untuk mencetak kartu identitas berobat. Adapun saran penulis sebagai berikut, kepala rekam medis sudah mengupayakan kepada pimpinan direktur agar proses pembuatan kartu identitas berobat dapat dikerjakan secara komputerisasi, segera diupayakan untuk diadakan alat cetak atau printer di bagian pelayanan pendaftaran agar dapat mempercepat pekerjaan atau pelayanan pendaftaran secara optimal dan efektif.
\end{abstract}

Kata kunci: Perancangan; Kartu identitas berobat; Visual Studio.

\section{Abstract}

At this time the development of technology is growing and advancing in any field, including in the field of health and the scope of the hospital.However, there are still many traditional methods (manuals) that are still used by humans. Within the scope of the hospital, one of the manual methods that is still used is the identity card for treatment. The manufacture ofidentity card for treatment. The manufacture of identity card for treatment which is still manually using raw materials in the form of paper. This can reduce efficiency and time effectiveness, so it is necessary to design a modern identity card for treatment manufacture. This study aims to design a medical idetity card using visual studio 2010 at Muhammadiyah Bandung Hospital. The research method used is qualitative research method. Data collection techniques 
used are by observation through interviews and completed with literature review. Some of the problems that occur during the outhor doing field practice, still the manuals in making patients' medical idetity card, there is no printer tool to print out medical identity card. As for the author's advice the Head of the medical record has been trying to leader of the director for the process of making medical identity card for outpatients can be worked on the computerized, immediately attempted to be held printing equipment or printers at the registration service that can speed up the work or registration services optimally and effectively.

Keywords: Designer; Medical Identity Card; Visual Studio.

\section{Pendahuluan}

Rumah sakit merupakan bagian dari sistem pelayanan kesehatan masyarakat yang harus mengedepankan pelayanan sebaik-baiknya kepada masyarakat sebagai objek utama. Maka dari itu, Rumah Sakit membutuhkan manajemen yang baik agar kegiatan pelayanan dapat berjalan dengan lancar. Pelayanan yang baik tentunya harus didukung sistem data pasien yang baik pula.

Era saat ini adalah era informasi, dan masyarakat perlu meningkatkan pengetahuannya, termasuk di bidang kesehatan (Jaya, Wulandari, \& Susiloningtyas, 2021). Sebagai penyedia informasi kesehatan, rumah sakit harus mampu memberikan pelayanan informasi yang cepat dan akurat. Rumah sakit adalah tempat pasien mencari dan menerima pelayanan medis, serta tempat pendidikan klinis mahasiswa kedokteran, perawat dan berbagai tenaga kesehatan lainnya (Kurniati, 2019).

Di rumah sakit salah satu pelayanan medis dan penunjang. Salah satu contoh pelayanan penunjang yaitu bagian rekam medis. Rekam medis merupakan pintu pelayanan kesehatan, ruang lingkup rekam medis yaitu berkisar dari penerimaan pasien pada saat pendaftaran hingga penyajian informasi kesehatan (Sudra et al., 2021).

Rekam medis adalah berkas yang berisikan catatan dan dokumen tentang identitas pasien, pemeriksaan, pengobatan, tindakan dan pelayanan lain yang telah diberikan kepada pasien baik pelayanan rawat jalan, rawat inap maupun gawat darurat. Setiap pasien yang datang berobat ke rumah sakit akan mempunyai berkas rekam medis ( Depkes RI, 2011).

Kegiatan rekam medis pertama kali dilakukan dibagian pendaftaran. Salah satu penunjang kelancaran bagian pelayanan pendaftaran adalah tersedianya kartu identitas berobat (KIB) khususnya untuk pasien lama. Namun jika pasien tidak membawa KIB akan memperlambat pencarian nomor rekam medis dan memperlambat penyediaan berkas. KIB mempermudah petugas dalam mengetahui data pasien dan nomor rekam medis pasien tersebut.

Menurut (Sudra, 2013) menyatakan bahwa KIB merupakan tanda pengenal yang harus dibawa setiap kali berobat sama baik rawat jalan maupun rawat inap dan difungsikan untuk melihat nomor rekam medis pasien. Informasi yang terkandung dalam KIB adalah nama pasien tanggal lahir serta nomor rekam medis pasien tersebut. KIB merupakan kunci untuk mengetahui nomor rekam medis pasien. 
Rumah Sakit Muhammadiyah menggunakan KIB berbasis manual atau kertas akan tetapi hal ini tidak efisien karena sering terjadi kerusakan terhadap KIB yang pasien miliki seperti kertas yang sering kali kusut tulisan tidak terbaca jelas bahkan robek, hal ini berdampak mempengaruhi kepada pelayanan yang sedikit melambat.

Rumah sakit dapat membuat kebijakan sesuai dengan perkembangan ilmu pengetahuan dan teknologi hal ini bertujuan untuk meningkatkan pelayanan kesehatan. Khususnya dalam pembuatan KIB secara elektronik atau berbasis komputerisasi, hal ini dapat mempermudah dan mempercepat proses pelayanan. Alat yang digunakan dan yang diperlukan adalah komputer dan printer.

\section{Metode Penelitian}

Dalam menyelesaikan penelitian ini penulis menggunakan metode penelitian kualitatif dengan pendekatan deskriptif yaitu suatu peneliian yang bertujuan menggambarkan (deskripsi) tentang keadaan tertentu secara objektif.

Menurut (Sugiyono, 2010) metode penelitian kualitatif adalah metode penelitian yang digunakan untuk meneliti pada kondisi objek yang alamiah, dimana peneliti adalah sebagai instrument kunci.

\section{Teknik Pengumpulan Data}

a. Penelitian Lapangan (Observasi)

Metode ini dilakukan dengan cara mengamati secara langsung keadaan dan kegiatan rumah sakit terutama pada bagian pendaftaran guna mendapatkan keterangan yang akurat.

b. Wawancara (Interview)

Menurut (Rojabi, 2019) Wawancara merupakan pengumpulan data atau inofrmasi yang dilakukan dengan menggunakan pertanyaan yang disampaikan langsung kepada sumber informasi dalam hal ini, peneliti melakukan wawancara dengan petugas rekam medis terutama dengan petugas bagian pedaftaran dan kepala rekam medis di Rumah Sakit Muhammadiyah Bandung.

\section{Model Perancangan}

Menurut (Putra, 2020) System Development Life Cycle (SDLC) adalah siklus atau tahapan yang digunakan dalam pembuatan pengembangan suatu sistem informasi agar pengerjaan sistem berjalan secara terstruktur, efektif dan sesuai dengan tujuan yang diinginkan. SDLC terdiri dari beberapa tahapan yaitu, mulai dari tahap perencanaan (Planning), tahapanalisis (Analysis), tahap perancangan (Design),tahap implementasi (Implementation), dan tahap pemeliharaan system (Maintenance). 


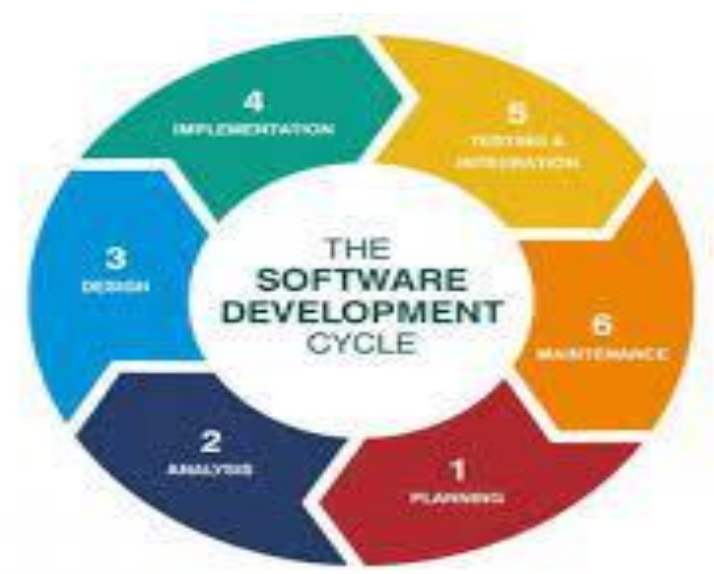

Gambar 1 Metode SDCL

\section{Perencanaan(Planning)}

Tahapan awal dimana merecanakan rencana apa saja yang akan dilakukan dalam perancangan ini.

2. Analisis(Analysis)

Analisa kebutuhan yaitu melakukan analisis terhadap permasalahan yang dihadapi dan menetapkan kebutuhan perangkat lunak, fungsi performasi dan antarmuka (interface) yang dibutuhkan.

3. Perancangan(Design)

Tahapan dimana dilakukan penuangan pikiran dan perancangan sistem teradap solusi dari permasalahan yang ada dengan menggunakan perangkat pemodelan sistem. Pada penelitian ini penulis menggunakan diagram aliran data (Data Flow Diagram), Entity Relationship Diagram (ERD).

4. implementasi(Implementation)

Pada tahap ini dilakukan uji coba dan mengimplementasikan rancangan.

5. pemeliharaansistem(Maintenance)

Tahap ini menangani perangkat lunak yang suda selesai supaya dapat berjalan lancar dan terhindar dari gangguan-gangguan yang menyebabkan kerusakan.

\section{Hasil dan Pembahasan}

\section{Analisis Sistem}

Pembuatan kartu identitas berobat di rumah sakit ini masih secara manual. Membandingkan prosedur manual, menunjukan banyaknya kartu identitas berobat yang cepat rusak dan banyaknya petugas rekam medis yang kesulitan dala membaca kartu identitas berobat.

Perancangan KIB yang berbasis komputerisasi di rumah sakit adalah sebuah sistem komputerisasi yang memproses serta memudakan petugas dalam melayani pasien untuk mencapai tujuan rumah sakit yaitu peningkatan mutu pelayanan kesehatan di rumah sakit. 
Ridha Robiatul Adhawiyah, Yuyun Yunengsih, Falaah Abdussalaam

\section{Spesifikasi Proses}

\section{Flowmap Sistem yang akan Berjalan}

Flowmap adalah kombinasi Antara peta dengan flowchart, yang menunjukan pergerakan alur benda dari satu area ke area lain (Mitha, 2016).

Proses pendaftaran pasien meliputi:

1. Pasien datang kebagian pendaftaran dan mengisi formulir pendaftaran.

2. Lalu petugas akan meng-input data pasien untuk kartu identitas berobat.

3. Setelah itu KIB elektronik akan di cetak melalui sistem yang sudah di buat.

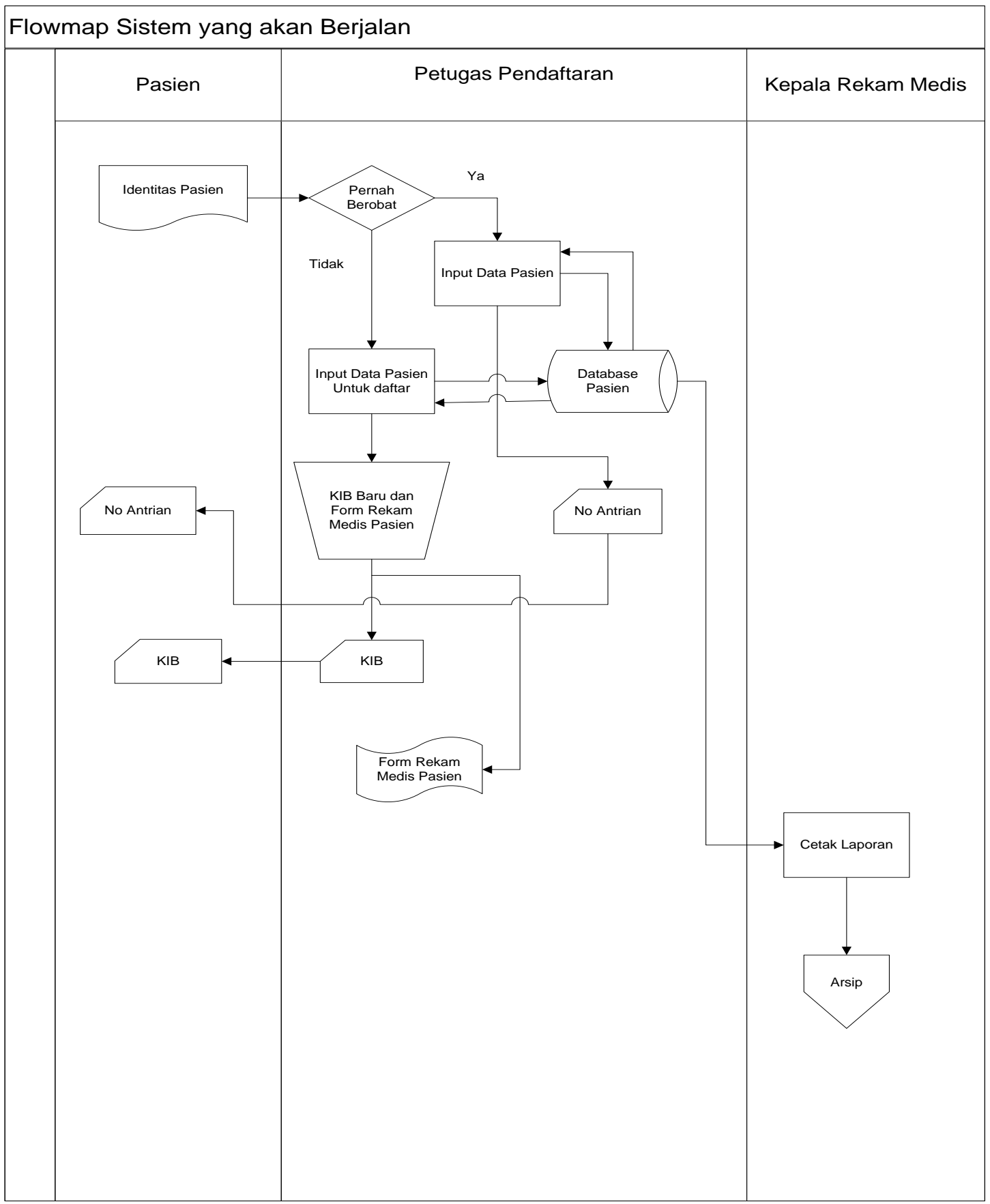

Gambar 2 FlowmapSistem yang akanBerjalan 


\section{Diagram Konteks}

Diagram konteks adalah diagram yang terdiri dari suatu proses dan menggambarkan ruang lingkup suatu sistem. Diagram konteks menggambarkan seluruh masukan input yang diterima sistem dan keluaran output yang dihasilkan oleh sistem (Waskhas, 2016).

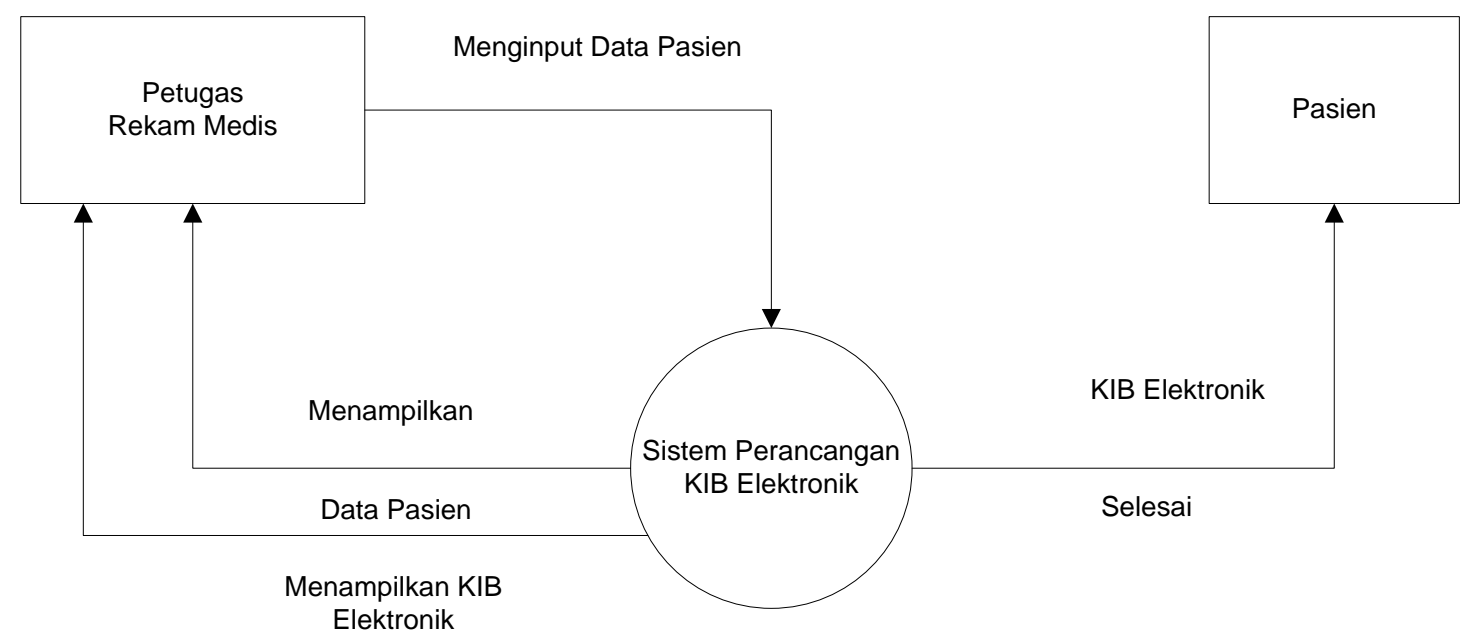

Gambar 3 Diagram Konteks

\section{Data Flow Diagram Level 0}

Data Flow Diagram atau DFD yaitu suatu teknik untuk membuat suatu kerangka sistem yang berorientasi pada alur data yang bergerak pada sebuah perancangan system lainya. Menurut (Waskhas, 2016) DFD juga dapat diartikan sebagai diagram yang menggambarkan proses dari dataflow diagram. Diagram nol memberikan pandangan secara menyeluruh mengenai sistem yang ditangani, menunjukan tentang fungsi-fungsi utama atau proses yang ada, aliran data, dan eksternal entity. Pada bagian ini, aliran data yang mengalir dan rancangan sistem kartu identitas berobat elektronik. 
Ridha Robiatul Adhawiyah, Yuyun Yunengsih, Falaah Abdussalaam

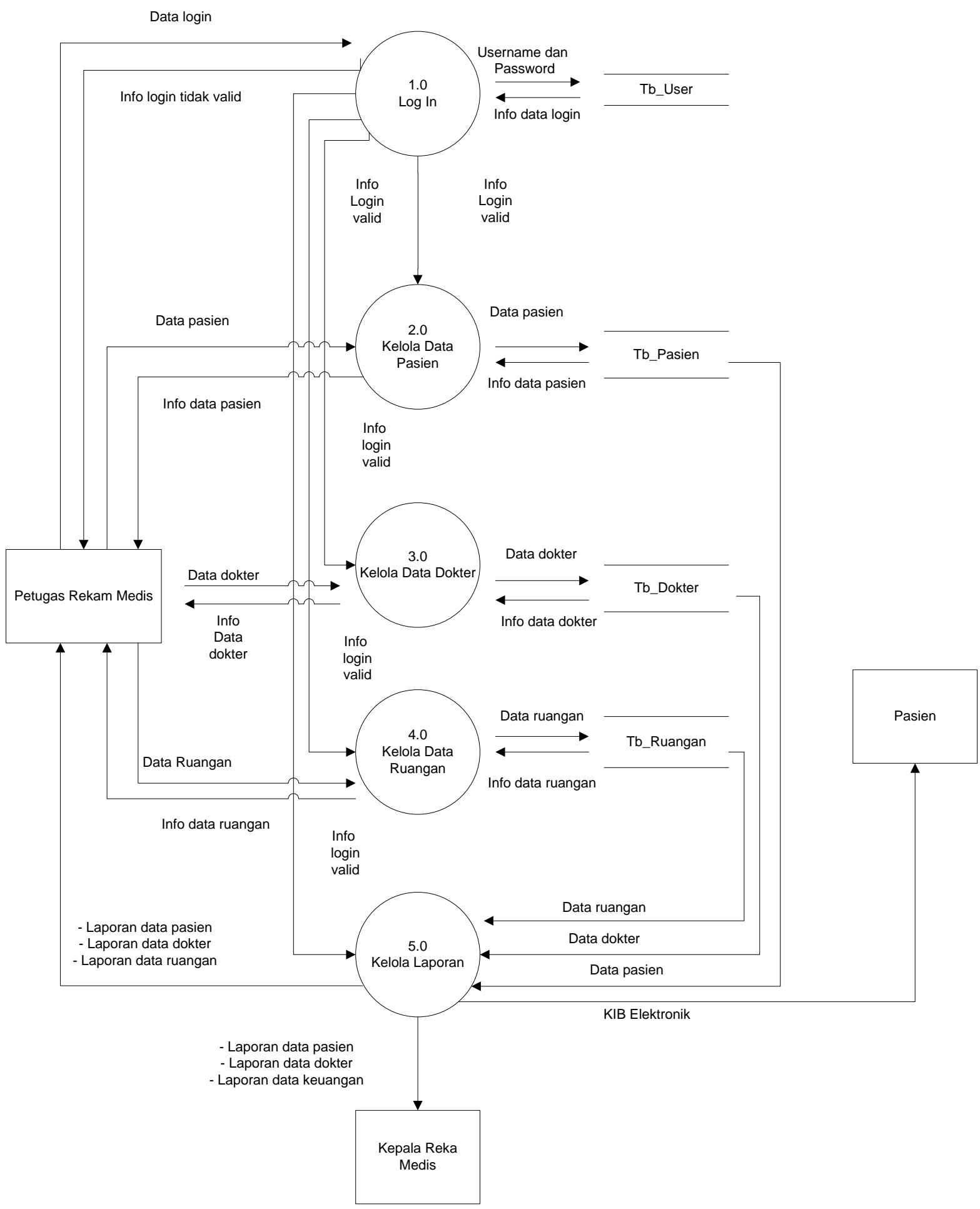

\section{Gambar 4 DFD Level 0}

\section{Entity Relationship Diagram (ERD)}

Merupakan representasi grafis dari logika database dengan menyertakan deskripsi detail mengenai seluru enitas, hubungan, dan batasan. Menurut (Tristin, 2021) merupakan 
Perancangan Kartu Identitas Berobat Elektronik dengan Menggunakan Visual Studio di Rumah Sakit Muhammadiyah Bandung

sebuah model untuk menyusun database agar dapat menggambarkan data yang mempunyai relasi dengan database yang akan didesain.

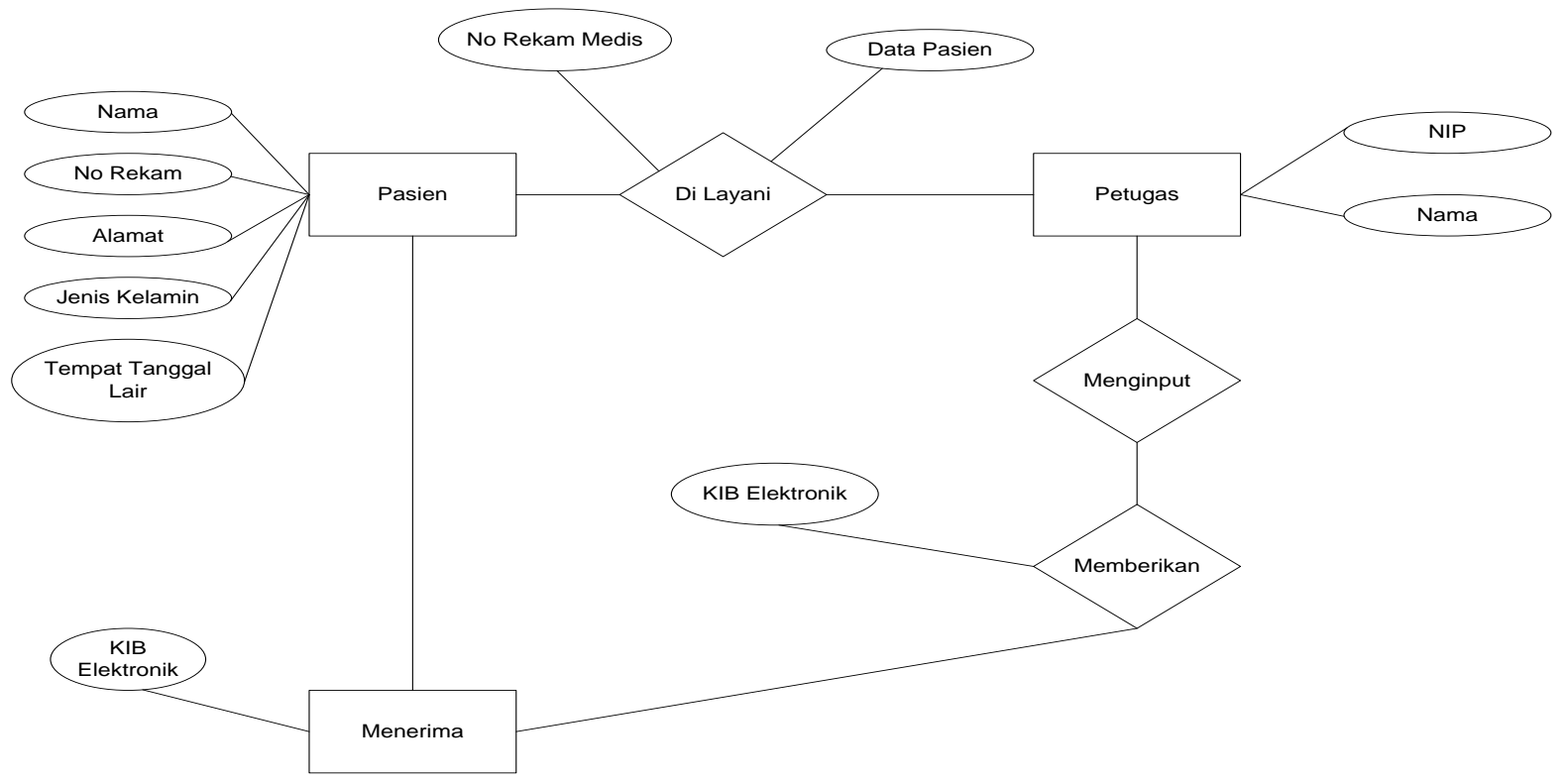

Gambar 5 ERD

\section{Tampilan Rancangan Layar}

1. Layar Menu Login

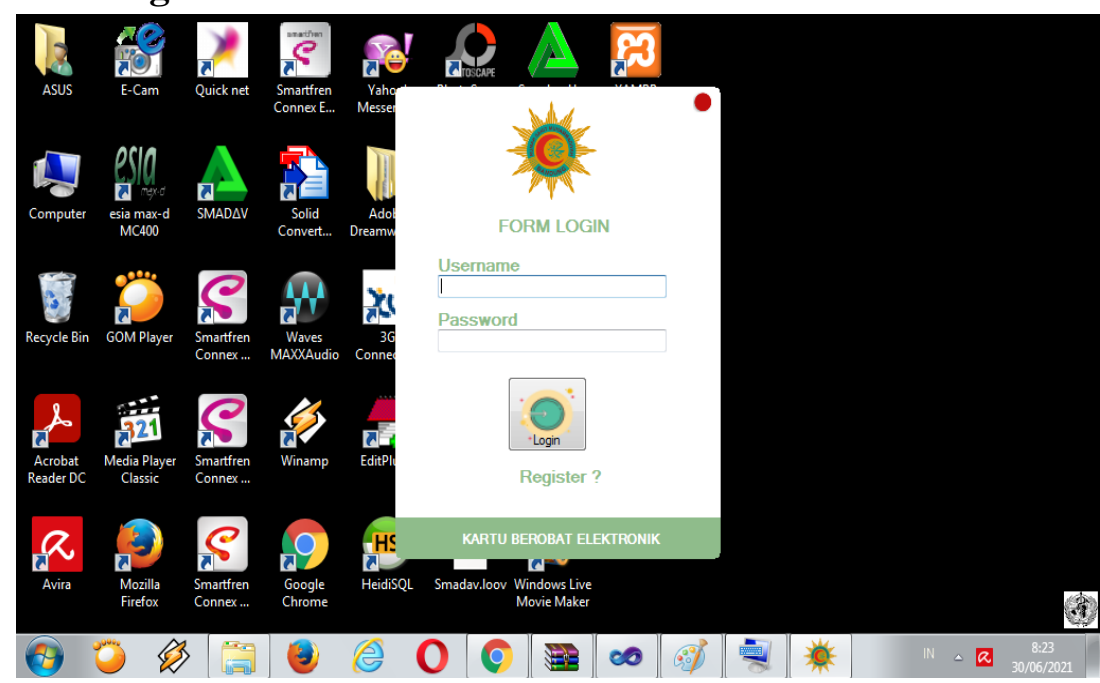

Gambar 6 Menu Login 


\section{Layar Kelola Data Pasien}

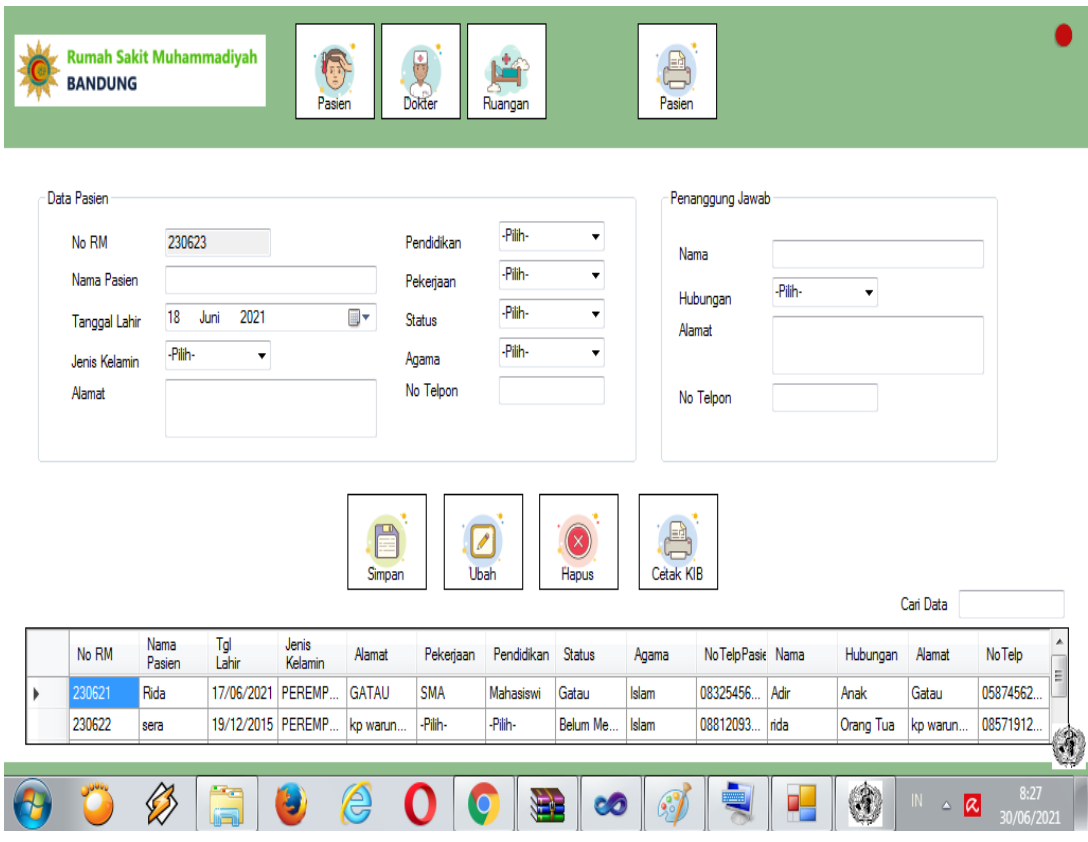

\section{Gambar 7 Kelola Data Pasien}

\section{Layar Cetak Kartu Berobat Pasien}
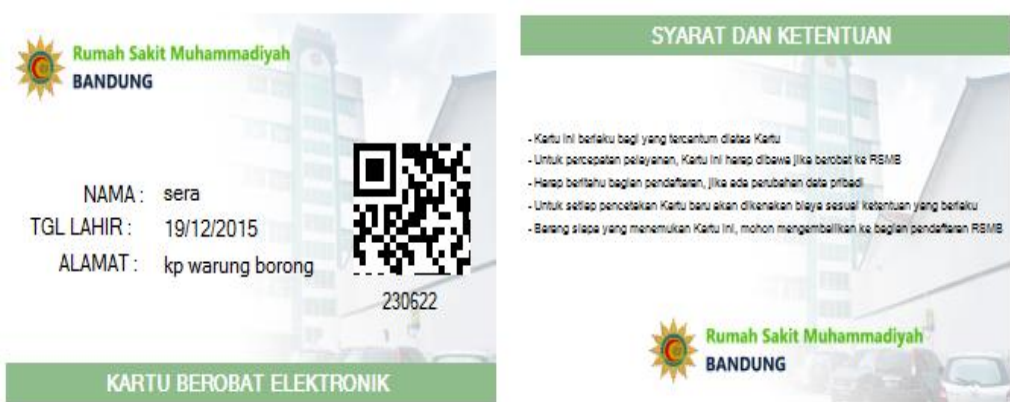

Gambar 8 Kertu Berobat Pasien

\section{Kesimpulan}

Setelah melakukan observasi dan praktek kerja lapangan (PKL) di Rumah Sakit Muhammadiyah Bandung, maka penulis dapat menarik kesimpulan yaitu:

Rumah Sakit Muhammadiyah Bandung merupakan rumah sakit yang menggunakan KIB secara manual sehingga perlu adanya sistem yang dapat mepermudah penggunaan KIB agar lebih efektif dan efisien. Dengan adanya KIB elektronik ini, maka proses pencarian berkas rekam medis pasien agar lebih mudah dan mempercepat dalam melakukan pelayanan, menghema waktu dan tenaga dari petugas rekam medis serta menghemat kertas untuk bahan baku. 
Perancangan Kartu Identitas Berobat Elektronik dengan Menggunakan Visual Studio di Rumah Sakit Muhammadiyah Bandung

\section{Bibliografi}

Jaya, Susanti Tria, Wulandari, Ratna Feti, \& Susiloningtyas, Luluk. (2021). Pendidikan Kesehatan PHBS Kader Kesehatan Era New Normal di Desa Darungan. Journal of Community Engagement in Health, 4(1), 162-166.

Kurniati, Dewi. (2019). Penerapan Management K3RS.

Mitha. (2016). Sistem manajemen. https://sisteminformasimanajemen15089.wordpress.com

Putra. (2020). Pengertian SDCL. https://salamadian.com/sdlc-system-development-lifecycle/

RI, Depkes. (2011). ProfilKesehatan Indonesia.

Rojabi, Ahmad Ridho. (2019). Blended Learning via Schoology as a Learning Management System in Reading Class: Benefits and Challenges. Jurnal Linguistik Terapan, 9(2), 36-42.

Sudra, Rano Indradi. (2013). Rekam Medis. Tangerang Selatan: Universitas Terbuka.

Sudra, Rano Indradi, Dewi, Ratih Kumala, Widiyanto, Wahyu Wijaya, Sihotang, Jay Idoan, Jamaludin, Jamaludin, Argaheni, Niken Bayu, Koibur, Mayko Edison, \& Purnawinadi, I. Gede. (2021). Manajemen Informasi Kesehatan. Yayasan Kita Menulis.

Sugiyono, Dr. (2010). Metode penelitian kuantitatif dan R\&D. Bandung: Alfabeta.

Tristin. (2021). Entiy relationship diagram. https://www.dewaweb.com/blog/entityrelationship-diagram/

Waskhas. (2016). Pengertian DFD dan contoh diagramnya. www.waskhas.com./2016/05/pengertian-dfd-dan-contoh-diagram-nya-html 